\title{
A Study on the Influence of the Conglomerate Mesostructure on Fracture Failure Behavior Based on Discrete Element Method
}

\author{
Yu Yan ${ }^{1}{ }^{1}$ and Shiyuan $\mathrm{Li} \mathbb{D}^{1,2}$ \\ ${ }^{1}$ Department of Engineering Mechanics, College of Petroleum Engineering, China University of Petroleum, Beijing 102249, China \\ ${ }^{2}$ State Key Laboratory of Petroleum Resources and Prospecting, China University of Petroleum, Beijing 102249, China \\ Correspondence should be addressed to Shiyuan Li; lishiyuan1983@cup.edu.cn
}

Received 19 July 2020; Revised 30 December 2020; Accepted 8 January 2021; Published 27 January 2021

Academic Editor: Hang Lin

Copyright (c) $2021 \mathrm{Yu}$ Yan and Shiyuan Li. This is an open access article distributed under the Creative Commons Attribution License, which permits unrestricted use, distribution, and reproduction in any medium, provided the original work is properly cited.

\begin{abstract}
Rich in valuable reserves, conglomerate reservoirs in China have gradually emerged as a fundamental development source. Currently, research pertaining to the macromechanical properties of crack propagation in conglomerates is conducted either by directly employing various physical tests or by formulating a simplified numerical model for simulation, while disregarding the influence of the conglomerate mesostructure. In this paper, the analysis is performed by adopting techniques such as CT scanning and Particle Flow Code (PFC) numerical simulation. CT scanning is used to identify the mesoscopic structure of the conglomerate, and then, a numerical model is devised in accordance with the CT scanned digital image. Three-point bending simulation experiments are conducted for 3 sets of semicircular conglomerate specimens possessing prefabricated cracks, to analyze the influence of the initiation and evolution of mesostructure on the fracture failure behavior. Research suggests: (1) The mesostructure within the conglomerate is complexified due to the presence of gravel. Conglomerate specimens exhibiting different mesostructures tend to diversify the possible modes of destruction of the conglomerate. (2) A fluctuation is noticed at peak load under the fracture toughness test. The numerical simulation of the fracture toughness undertaken via the PFC method revealed the reason for the peak load fluctuation during the fracture propagation to be the constant penetration of the cracks into or out of gravel particles. (3) The fracture toughness simulation tests ascertain the existence of certain fracture characteristic units during the fracture propagation process, wherein the evolution of the internal mesostructure considerably influences the macroscopic failure mode of the conglomerate.
\end{abstract}

\section{Introduction}

Although conglomerate reservoirs are rich in resources and have ample reserves, the peculiarity of the mesostructure and the intricacy of the macro-meso mechanical property of the conglomerate make the development of conglomerate reservoirs a highly challenging task (Figure 1). With respect to the field of rock mechanics, evaluation of the rock mechanical properties of the conglomerate cores has emerged as a pivotal concern in the petroleum engineering domain.

Considering the general oil reservoir development, the characteristic of rock heterogeneity affects the mechanical properties of the rock substantially, especially guiding the direction of initiation as well as the extension of hydraulic fractures. During the development of conglomerate reser- voirs, the attribute of rock heterogeneity becomes particularly significant due to its unique mesostructure, which can be primarily attributed to the presence of gravel. All the gravel factors, such as the size, quantity, distribution, and degree of cementation, significantly influence the mechanical properties of the conglomerate. Studies over the years have suggested that the various mesostructures formed within the conglomerate core by the gravel particles affect various engineering parameters, including fracture initiation and instability pressure, bottom hole pressure fluctuation and fluctuation period, and fluid conductivity resistance of the fracture [1-3].

In the due course of the investigation, it was realized that ongoing research on the mechanical properties of conglomerate fracture is predominantly centered on the assessment 


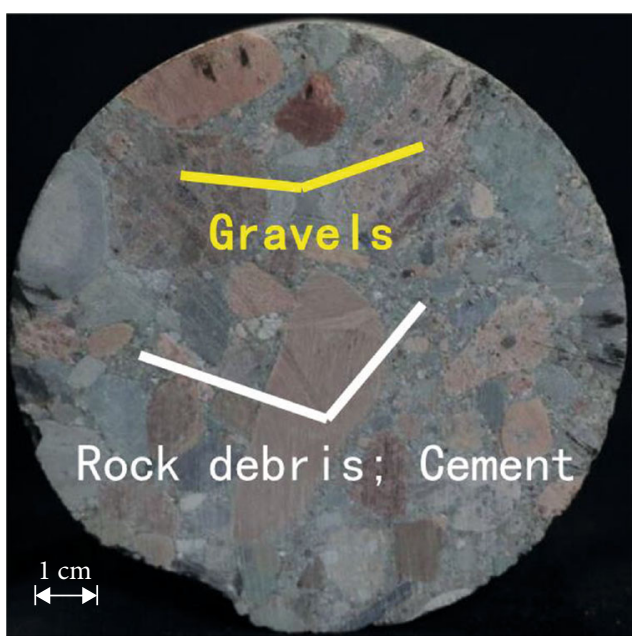

FIGURE 1: Rock conglomerate core. The core in the picture is $10 \mathrm{~cm}$ in diameter and comes from a reservoir with a depth of more than $2000 \mathrm{~m}$.

of fracture mechanics during hydraulic fracturing. Meng et al. [4] and Li et al. [5] explored various fracturing and acidizing processes, such as large-scale fracturing, energyenhancing fracturing, and thickened acid fracturing, based on the characteristics of sandy conglomerate reservoirs. Reinforcing technology that facilitates the analysis of diverse sand and conglomerate reservoirs has been developed over the years. The manner of influence of the gravel size in conglomerates under hydraulic fracturing was reviewed. The relationship between the construction pressure fluctuations and the particle size during hydraulic fracturing in conglomerate formations is discussed. $\mathrm{Li}$ et al. [2] and $\mathrm{Li}$ et al. [5] examined the initiation mechanism of hydraulically induced cracks. Considering the features of a standard sandy conglomerate reservoir in China, a numerical analysis on the characteristics of hydraulic fracturing fracture propagation mechanism of sandy gravel with varied gravel contents was conducted, followed by the assessment of the factors regulating the interface between the gravel and the matrix sandstone. $\mathrm{Li}$ and Wong [6] also reviewed the development and application of the Brazilian disc test for the conglomerate core and evaluated the test results for the same. Luo et al. [3] examined the causes triggering the irregular extension of hydraulic fractures and pressure fluctuations at various gravel scales, in accordance with the numerical simulation method applied to fracture mechanics and optimized the hydraulic fracturing design and construction parameters of sandy conglomerate reservoirs. Li et al. [7] studied and evaluated the effects of horizontal stress difference, gravel size, distribution law of gravel, and the viscosity and displacement of fracturing fluid on the hydraulic fracture propagation during the hydraulic fracturing process. Even though most of the abovementioned studies draw conclusions that are explanatory of the mechanical behavior of conglomerate cores, especially in terms of the macroscopic experimental study of conglomerates, majority of the scholars have primarily based their research on the final fracture morphology while studying the mechanical properties of conglomerate rock. These analyses have mostly disregarded the significant influence produced by the formation and evolution of mesostructures on the crack propagation process.

Regarding the aforementioned concerns, Yang and Tan [8] pointed out that there exist impassable limitations for the study of fracture failure in the macromechanics domain, and it is quite vital to consider it for the small-scale damages, such as the damage occurring in mesostructure of conglomerates. Bazant and Chen [9] advocated that majority of the material mechanics' scholars seldom contemplate the problem of scale rate and size effect of the materials. This shows that the previous studies on the mechanical properties of conglomerates were mostly limited to the testing and analysis of macromechanical properties. Furthermore, Bai et al. [10] proposed that the fundamental complexity of exploring the "collapse" problem from a meso-mechanical perspective lies in the existence of varied microstructure levels and diverse evolutionary physical dynamics and rates at different scales in the solids. Hence, here we attempt to comprehensively consider and investigate the influence of the mesostructure of conglomerates on its mechanical properties, while also evaluating the mechanical properties of the same. In this paper, it is assumed that the crack propagation modes, such as penetrating gravel and by-passing gravel, are regarded to be the outcome of the collapse of meso-cementation and the occurrence of macrofracture behavior. The crack evolutionary rates and the physics of these crack propagation modes appear to be different at different structure levels and scales. In order to better explain the collapse of conglomerates, it is essential to fully comprehend the relationship between the mesoscopic characteristics (including the degree of cementation, size, and spatial distribution between the gravel particles) and the macroscopic fracture behavior of the conglomerates.

Since conventional physical experiments are unable to meet this requirement, a study on the rock materials like conglomerate cores is conducted here, with the help of numerical simulation methods. Numerous scholars have carried out research in the area under consideration, but most of the relevant studies on conglomerates employing the discrete element method (DEM) tend to simplify the gravel into large, single, or circular (ball) elements while modeling. The results obtained by such simulation methods often demonstrate only the form of bypassing the gravel damage [11-14], while disregarding the influence generated by the mesostructure of the gravel. Even though several mechanical properties of the conglomerates can be derived by considering certain aspects, this method disregards the impact of the mesostructure variations triggered by the gravel on the macromechanical properties.

Jiang et al. [15] established a 2D discrete element particle contact model based on the particle rotation factor, considering the contact between particles as the surface contact, which compensated for the defects of circular particles to a certain extent. Belheine et al. [16] recommended a 3D contact model based on the rotational resistance of particles and simulated them considering the factual material parameters. Nonetheless, the antirotation contact model is hypothetical and based on phenomenology with no direct mechanical 
groundwork. In addition, several discrete element numerical simulation methods for noncircular particles have been carried out as well. For example, in the $2 \mathrm{D}$ cases, Rothenburg and Bathurst [17], Ng [18], and Wang and Wang [19] simulated elliptical particles. Kuhn [20] and Yan [21] generated ellipsoidal particles in a 3D manner and simulated diverse particle shapes by changing the ratio of the major and minor axes of the ellipse or ellipsoid. Peña et al. [22], Mollon and Zhao [23], and Liu et al. [24] obtained arbitraryshaped polygonal particles, and Azema et al. [25] and Lee et al. [26] simulated random polyhedral-shaped particles in a $3 \mathrm{D}$ manner.

Several studies [27-30] also proposed different methods for generating irregularly shaped particles, mainly by manipulating particle sphericity, roughness, and particle contours. They suggested embedding the generated particles in the bedrock or directly piling them up to simulate the macroscopic test of mechanical behavior of rock materials comprising of irregularly shaped particles under various situations. On the one hand, the application of these modeling methods could, to a certain extent, expose the impact of the mesoscopic structure comprising of irregular particles on the macroscopic mechanical behavior, overlooking the natural defects generated due to the simplification of the mesoscopic structure. On the other hand, these techniques also suffer certain shortcomings: they are incapable of reflecting the veritable mesostructure of rock materials, particularly in the conglomerates. Moreover, they are able to acquire the mechanical properties of rock materials comprising of only selective shapes, which in itself emerges as an individual simplified modeling method.

Employing an amalgamated outcome from the above researches and investigation results in terms of the mesomechanics viewpoint, this study utilizes the CT scanning technology to obtain the true mesoscopic structure of the conglomerate under consideration. Further, certain representative mesostructures from the CT results are selected to establish the PFC2D models designed for three-point bending simulation experiments on semicircular specimens with prefabricated cracks. The analysis of the simulation results is undertaken to describe the initiation and evolution process of the mesostructure of conglomerates under the loading to a fault, and it facilitates in comprehensively understanding the conglomerate failure process.

\section{Materials and Methods}

2.1. CT Scanning. Computerized Tomography, referred to as $\mathrm{CT}$ axial technology, is utilized to categorize the layers and process the two-dimensional images in three-dimensional volume. The three-dimensional sliced image is reconstructed three-dimensionally by employing a digital image processing method after acquiring the three-dimensional result from the CT scanning. This scanning method is capable of distinguishing between various mineral components in the rock materials (but cannot identify specific mineral species), classified according to the difference in the CT numbers determined by the density of different elements present in the rock. Furthermore, the mesostructures within

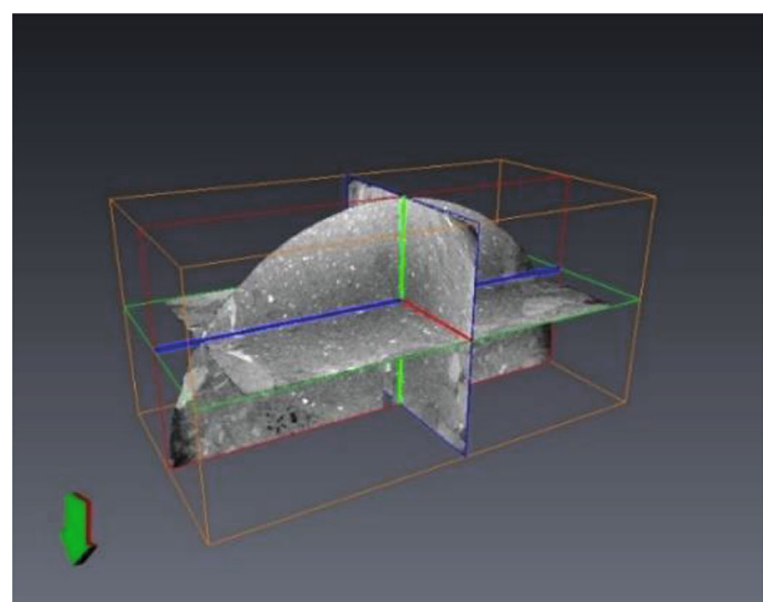

FIgure 2: Three-dimensional slices of CT images. The picture shows a semicircular core specimen with a diameter of $10 \mathrm{~cm}$. The thickness of each CT slice is about $60 \mu \mathrm{m}$, which means the size of each image pixel is $60 \mu \mathrm{m}$.

the rock (including rock texture, gravel boundaries, and gravel spatial distribution) can be reproduced as digital images (Figures 2 and 3).

In this study, 10 conglomerate core specimens were scanned by CT imaging utilizing the nanoVoxel-3502E CT scanner of Sanying Precision Instrument Co., Ltd. The CT scanner possesses a maximum resolution of $0.5 \mu \mathrm{m}$. The CT scan results were processed by the Avizo digital image processing software provided by Sanying Precision Instrument Co., Ltd.

2.2. Particle Flow Code. First proposed by Peter Cundall [31] in 1971, the Discrete/Distinct Element Method (DEM) was applied by him [32] to the domain of soil research and later published in two parts by Cundall [33]. A detailed drafting led to the formation of the Particle Flow Code (PFC) method. In 2004, Potyondy and Cundall [34] proposed a bondedparticle model (BPM). The BPM is capable of producing a reasonable simulation of the evolution of fibrous force chain of rock materials between the particles (Figure 4). Under the action of macroscopic external forces, the bonding formation and the mesoscopic fracture modes of the particles are based on a chain-like force or moment. The BPM serves as a satisfactory approach to explain the evolution of the fibrous force chain and functions as the key to the material destruction process. The model utilized in this study is a parallel bond model (Figure 5), derived from the BPM.

External force equation for parallel bonding is as follows:

$$
\begin{aligned}
F_{c} & =F^{1}+F^{d}+\bar{F}, \\
M_{c} & =\bar{M},
\end{aligned}
$$

where $F^{1}$ denotes a linear force (direct force of other particles), $F^{d}$ is a dissipative force, $\bar{F}$ represents a parallel bonding force, and $\bar{M}$ is a parallel bonding moment. In the BPM, when the load between the particles satisfies certain 


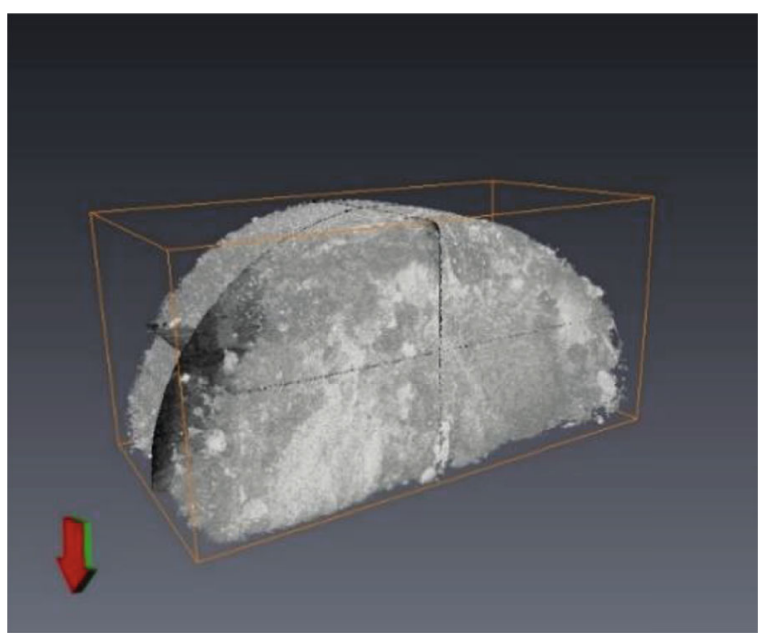

FIGURE 3: Three-dimensional volume of CT image. The size of the core sample and pixels in the figure are the same as those in Figure 2.

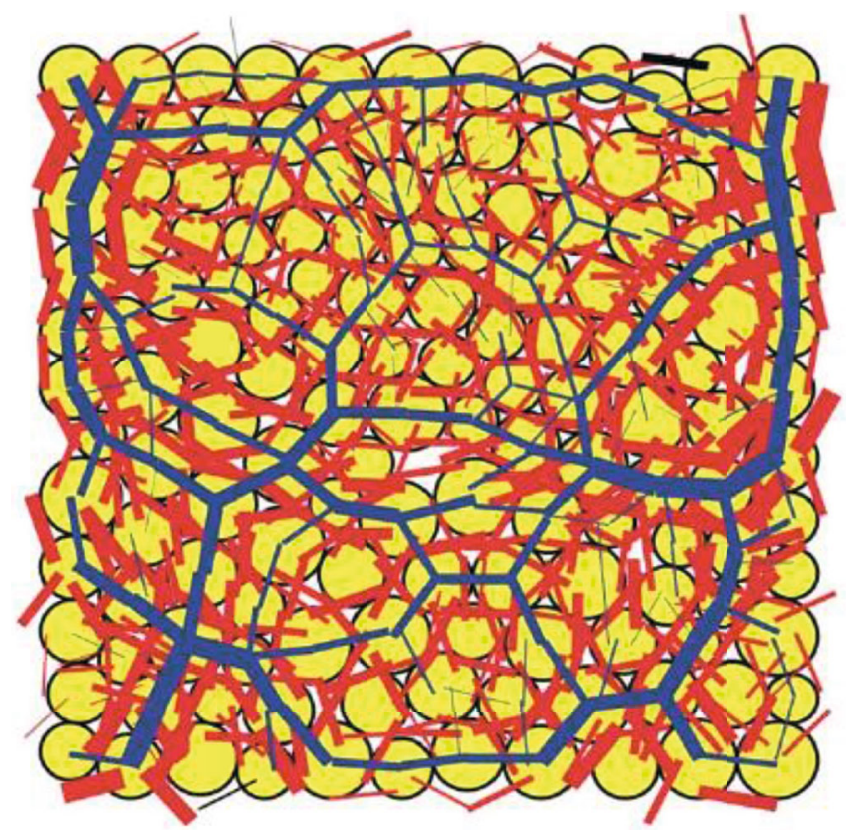

Figure 4: Particle bonding network ([34]). The red and blue lines in the figure represent the shear stress and normal stress between particles, respectively. The thickness of the line represents the value of the force.

conditions, the bond chain breaks, the bond between the particles disappears, and the material displays a fracture behavior under the microscope.

Based on the above principles, the contact stiffness equations between the particles are defined under numerical simulation by generating parallel bonding and particle contact stiffness parameters. During the simulation experiment, the failures of the test specimens were determined by monitoring the bond chain breakage between the particles. Simultaneously, the specific kind of breaking technique (tensile breaking, shear breaking) can be determined by detecting the manner in which the force chain breaks.

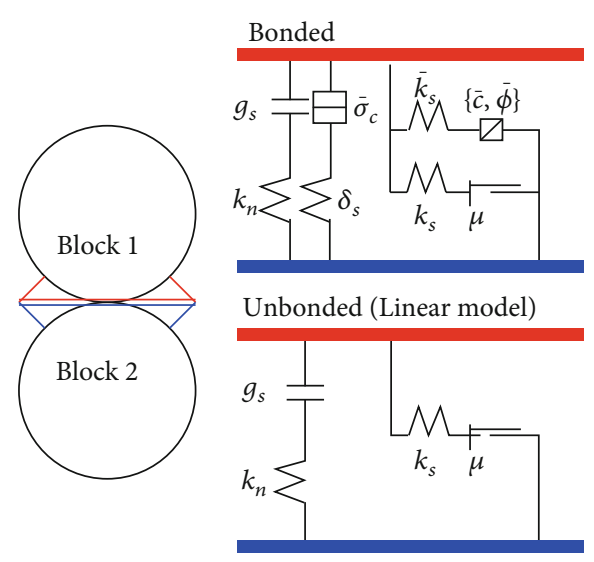

FIgure 5: Principle of parallel bonding. The red and blue lines in the figure represent the contact surfaces of the two elements, respectively. In the bonded state, the two elements are bonded, and the contact force between the elements is the algebraic sum of the contact force and the bonding force. The bonded state will be destroyed after the bonding force reaches a certain value, after which only contact force exists between the elements.

\section{Results and Discussion}

\subsection{Simulation Scheme}

3.1.1. CT Conglomerate Mesostructure Identification. The CT image utilized in this paper is a 16-bit grayscale digital image. The image is threshold-segmented by administering it under a specific threshold range. Then, the complete image is interspersed in order. When the grayscale pixel value of the image is larger than or equal to the threshold, it is considered to be a certain kind of substance, which could be determined by a set of guidelines or categories adopted. When the pixel gray value is less than the threshold, it is considered to be another substance from the categories. The simplest gray image binarization process can be expressed as:

$$
F(i, j)=\left\{\begin{array}{l}
1, \text { if } f(i, j) \geq T \\
0, \text { if } f(i, j)<T
\end{array}\right.
$$

Among them, $f(i, j)$ is the original threshold function, which appears to be a function of CT number $\left(n_{\mathrm{CT}}\right) ; F(i, j)$ is the divided threshold function; $T$ is the selected threshold range.

Due to the complexity of the mesostructure and the mineral composition of the conglomerates, the main threshold is divided into multiple thresholds, and different minerals are represented via different colors in the results obtained, in order to simplify the differentiation (Figure 6).

Considering the threshold predivision of the twodimensional CT images, the CT number range of the gravel and the matrix can be determined in accordance with the presence of a clear gravel boundary as the main criterion (Figure 7).

Finally, a three-dimensional area above the prefabricated crack is selected, and the three-dimensional structure of the gravel and the matrix is extracted, so as to obtain a three- 


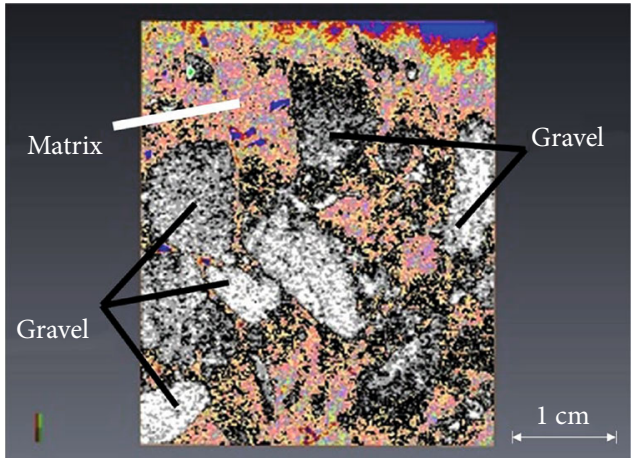

Figure 6: Results of threshold division. Color rendering is performed on different density areas. The white light areas are identified as gravel, and the other stained areas are rock matrixes, which include low-density clay minerals and some high-density rock debris.

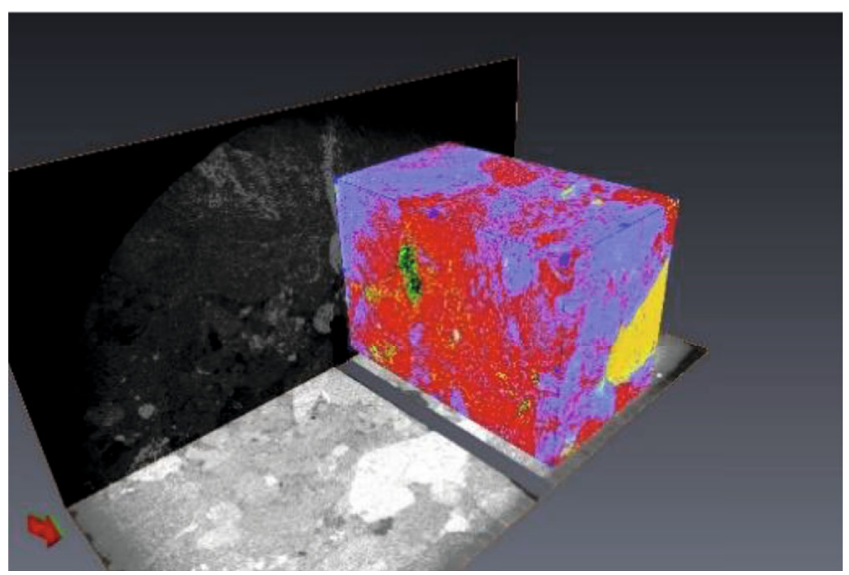

FIgURE 7: Spatial distribution of minerals in the subspace. The CT image of the entire core is preprocessed by selecting a specific subspace.

dimensional image of the spatial distribution of the mineral particles in the subspace (Figure 8).

By comparing the three-dimensional reconstructed core sample with the postphysical test core sample, it can be witnessed that the complex mesostructure formed by the gravel and matrix inside the conglomerate significantly influences the crack expansion. The specific content concerning this subject is discussed in detail in one of the other papers we have authored [35].

3.1.2. Numerical Simulation Based on PFC2D. Following the completion of the CT scanning results and analysis of the conglomerate mesostructure, three representative mesostructures are selected to simplify and construct a twodimensional model according to the location of the gravel and the direction of cracks post the simulation experiment.

Then, the computer-aided drafting (CAD) software is employed for mechanical design automation to model the structure and import it to PFC2D for numerical simulation (Figure 9). In Figure 10, the blue areas represent the gravel particles, and the green zone represents the conglomerate matrix.

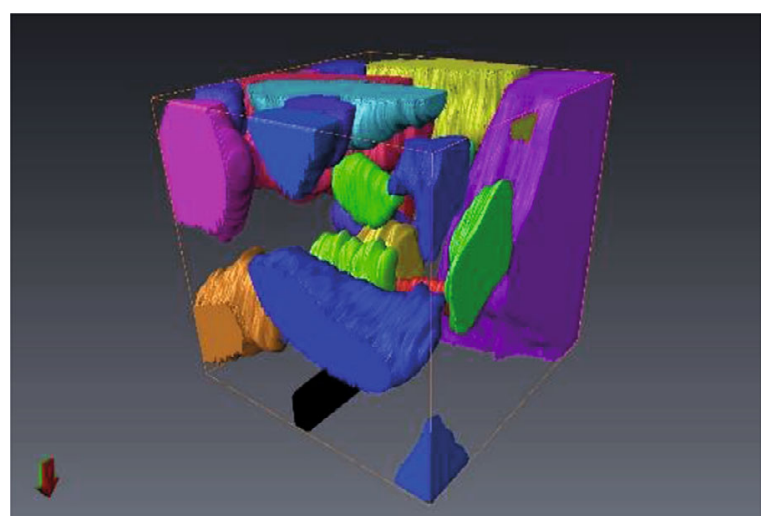

FIGURE 8: Spatial distribution of mineral particles in the original specimen. This figure represents a CT $3 \mathrm{D}$ reconstruction image of the distribution of the main gravel particles above the prefabricated cracks (black areas) of the sample. The size of the cube in the figure is $37161.66 \times 37161.66 \times 37161.66 \mu \mathrm{m}^{3}$. In the sample, there are about 29 gravels present in the cube area, and the average volume is $8.84 \times 1010 \mu \mathrm{m}^{3}$.

In the simulation initiated, the models used for the gravel, matrix, and interface in the core are all bonded-particle models (BPM). The core model is semicircular with a diameter of about $0.1 \mathrm{~m}$, and the length of the prefabricated crack is $0.02 \mathrm{~m}$. The size of the disc unit ranges from $0.0050 \sim 0.0075 \mathrm{~m}$, and the density is $2.5 \mathrm{~g} / \mathrm{cm}^{3}$. The final model is generated according to the core porosity of 0.1 , and the total number of units is 4,481 . In the Group A, the number of units in the matrix part is 2,242 , and the number of units in the gravel part is 2,239. In the Group B, the number of units in the matrix part is 2,867 , and the number of units in the gravel part is 1,614 . In the Group C, the number of units in the matrix part is 2,756 , and the number of units in the gravel part is 1,725 . The simulation models of each group are shown in Figure 10.

According to the meso-parameter research results of the matrix and gravel strength in the conglomerate proposed by Liu et al. [36] and using the method proposed by $\mathrm{Hu}$ [37], the meso-parameters were calculated, as shown in Tables 1-3. Based on the data tabulated below, the mesoparameters of various structures in the conglomerate are fixed. During the simulation, the upper and lower walls are applied in opposite directions but loaded at the same speed for testing. The termination condition is set to load control, and the application of the load is halted when the load on the upper wall loading point reaches less than $70 \%$ of the peak load.

\subsection{Study on the Response of Mesostructure during Fracture}

3.2.1. Deformation Behavior of Different Mesostructures. The deformation response produced by the external loads for various conglomerate specimens with different mesostructures displays different characteristics. The horizontal displacement in the three-point bending numerical simulation tests of three sets of semicircular specimens is shown in Figure 11. 


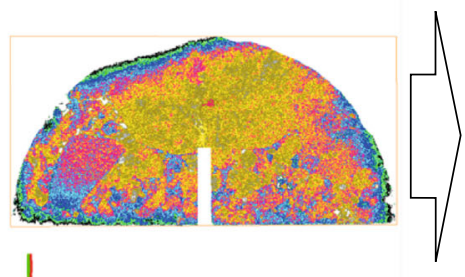

CT Photo

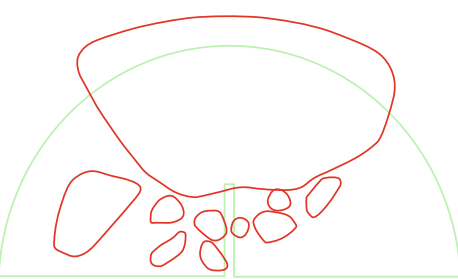

Contouring

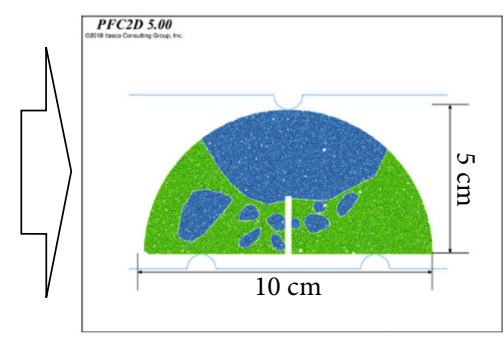

PFC model

FIGURE 9: Modeling process. After selecting the CT layer with a specific thickness position, the outline of the gravel is drawn using the CAD software and finally imported into PFC2D to form a model.

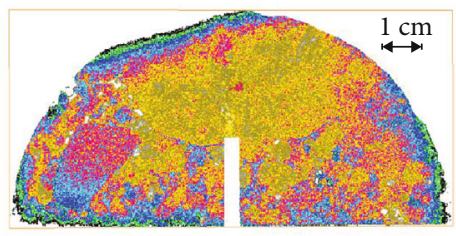

I

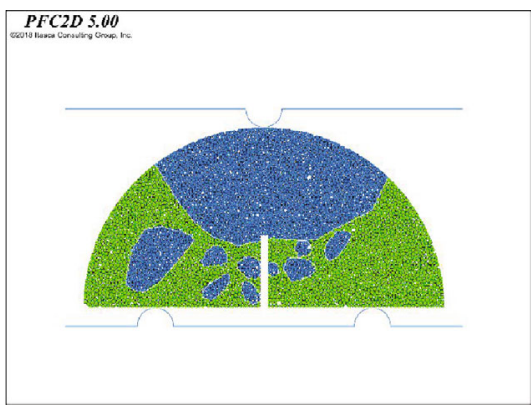

(a) CT image of Group A. Simulation models of Group A

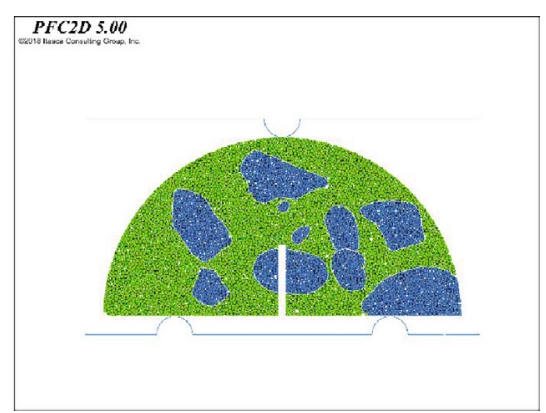

(b) CT image of Group B. Simulation models of Group B

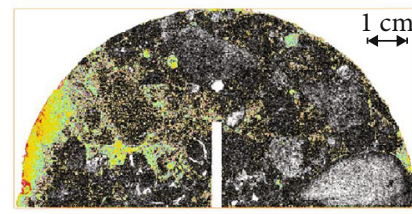

।

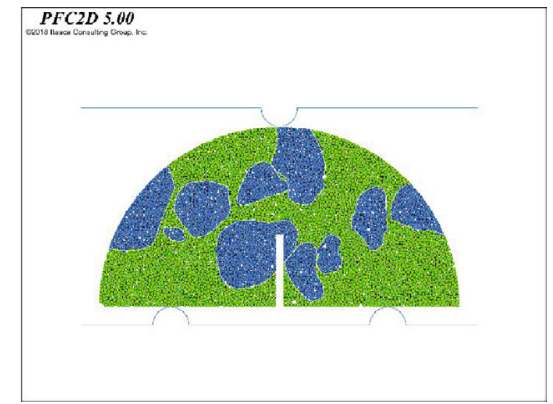

(c) CT image of Group C. Simulation models of Group C

FIGURE 10: Simulation models for fracture toughness tests. The selected three sets of test pieces are all semicircular with a diameter of $0.10 \mathrm{~m}$. Their mesoscopic structure is representative. There is a critical gravel above the prefabricated crack of specimen A. The rock matrix mainly exists above the prefabricated cracks of specimen B. The tip of the prefabricated crack in specimen $\mathrm{C}$ is inside the gravel, and there are matrix and multiple gravels above it.

The Group A in Figure 11 suggests that the gravel distribution of the specimens portrays good symmetry around the middle line. A large gravel block is present above the preset fracture, and the other gravel seems smaller. This kind of gravel distribution characteristic causes the overall external force on the conglomerate to be averaged during the loading process of the upper and lower walls, thereby generating a relatively uniform displacement field. Finally, a crack was 
TABLE 1: Simulation parameters of the rock matrix.

\begin{tabular}{lccc}
\hline Structure & Parameter & Default & Explanation \\
\hline & $E^{*}$ & $35 \mathrm{MPa}$ & Effective modulus (force/area) \\
& $\kappa^{*}$ & 1 & Normal/Shear stiffness ratio (-) \\
& $\bar{E}^{*}$ & $25 \mathrm{MPa}$ & Effective modulus of bonding (stress) \\
& $\bar{\kappa}^{*}$ & 1 & Normal/Shear stiffness ratio \\
Matrix & $\bar{\sigma}_{\mathrm{c}}$ & $100 \mathrm{kPa}$ & Tensile strength (stress) \\
& $\bar{c}$ & $80 \mathrm{kPa}$ & Cohesion (stresses) \\
& $\bar{\phi}$ & 20 & Friction angle (degrees) \\
& $\beta_{n}$ & 0.5 & Normal critical damping ratio (-) \\
& $\mu$ & 0.577 & Friction coefficient (-) \\
\hline
\end{tabular}

TABLE 2: Gravel simulation parameters.

\begin{tabular}{lccc}
\hline Structure & Parameter & Default & Explanation \\
\hline & $E^{*}$ & $20 \mathrm{MPa}$ & Effective modulus (force/area) \\
& $\kappa^{*}$ & 1 & Normal/Shear stiffness ratio (-) \\
& $\bar{E}^{*}$ & $75 \mathrm{MPa}$ & Effective modulus of bonding (stress) \\
& $\bar{\kappa}^{*}$ & 1 & Normal/Shear stiffness ratio \\
Gravel & $\bar{\sigma}_{\mathrm{c}}$ & $200 \mathrm{kPa}$ & Tensile strength (stress) \\
& $\bar{c}$ & $250 \mathrm{kPa}$ & Cohesion (stresses) \\
& $\bar{\phi}$ & 20 & Friction angle (degrees) \\
& $\beta_{n}$ & 0.5 & Normal critical damping ratio (-) \\
& $\mu$ & 0.577 & Friction coefficient (-) \\
\hline
\end{tabular}

TABLE 3: Interface simulation parameters.

\begin{tabular}{cccc}
\hline Structure & Parameter & Default & Explanation \\
\hline$E^{*}$ & $50 \mathrm{MPa}$ & Effective modulus (force/area) \\
& $\kappa^{*}$ & 1 & Normal/Shear stiffness ratio (-) \\
Interface & $\bar{\sigma}_{\mathrm{c}}$ & $10 \mathrm{MPa}$ & Tensile strength (stress) \\
& $\bar{c}$ & $10 \mathrm{MPa}$ & Cohesion (stresses) \\
& $\bar{\phi}$ & 20 & Friction angle (degrees) \\
& $\beta_{n}$ & 0.5 & Normal critical damping ratio (-) \\
& $\mu$ & 0.577 & Friction coefficient $(-)$ \\
\hline
\end{tabular}

propagated in the middle area of No. 1 gravel located above the prefabricated crack along the direction of the preset crack extension.

The Group B in Figure 11 implies that the size of the gravel block specimens appears similar, but the gravel distribution on the left is significantly lower than that on the right. This gravel distribution characteristic causes a large imbalance in the internal load on the rock specimen during the loading process, and the displacement field generated on the left side of the specimen is significantly greater than that on the right side. In this large instable displacement field, the symmetrical axis shifts to the right, and the crack propaga- tion direction basically extends upward along the prefabricated crack, but eventually, the crack ceases to extend after encountering No. 1 gravel.

The Group C in Figure 11 suggests that the gravel specimens are analogously sized, and the distribution is relatively uniform. This kind of gravel distribution characteristic causes the specimen to be subjected to a relatively uniform external force during the loading process, resulting in a relatively uniform displacement field. The evident center and symmetry axis of the displacement field appear in the sample, and the crack propagation direction is approximately the same as the prefabricated crack direction. 


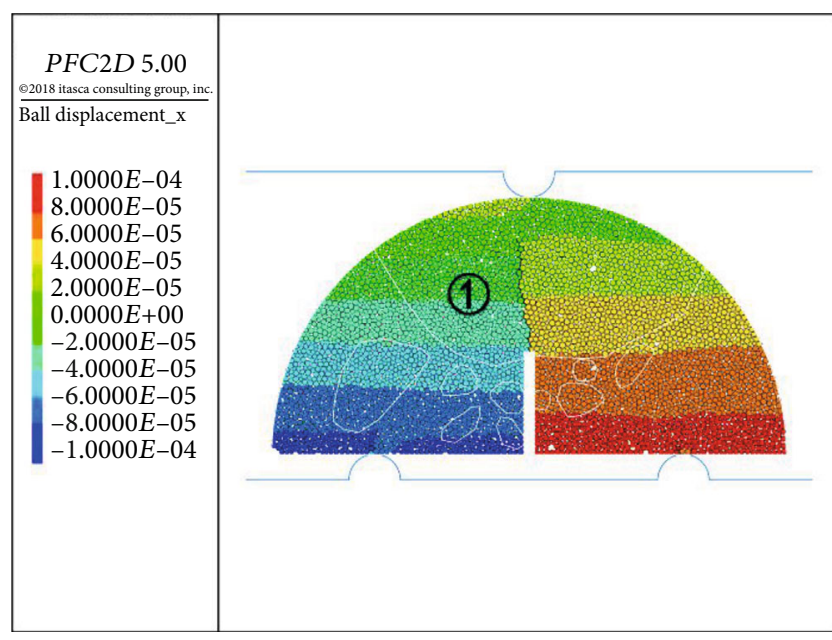

(a)

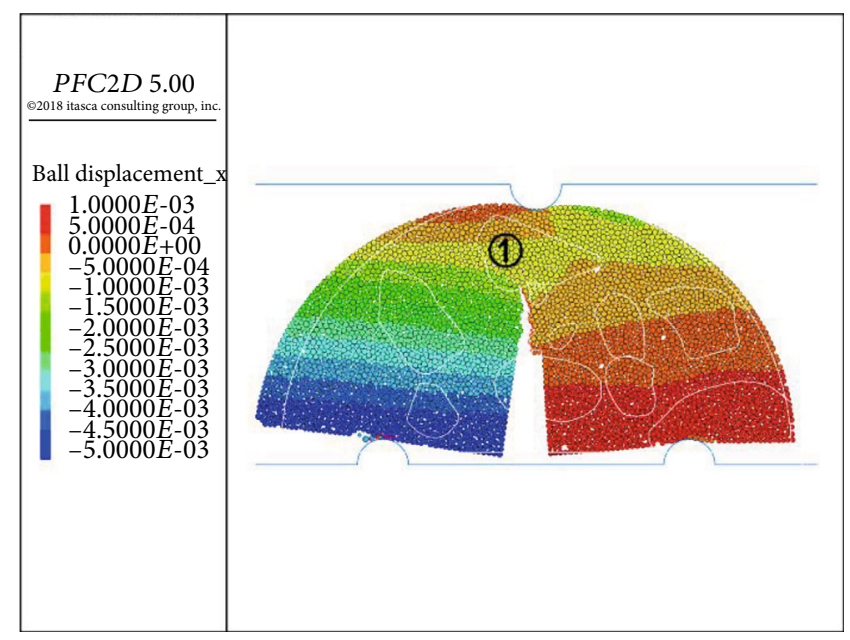

(b)

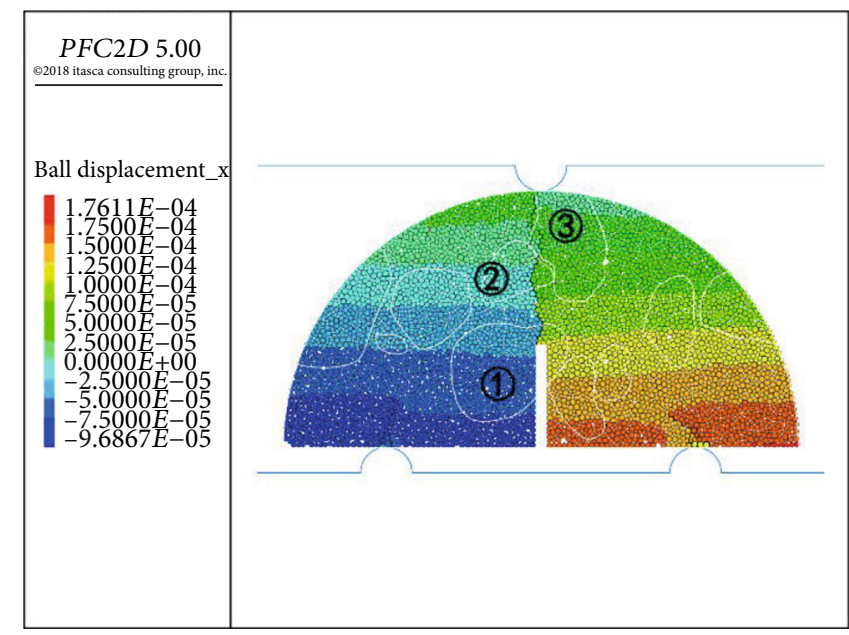

(c)

Figure 11: Simulation results of fracture toughness. Shown in the figure is the horizontal displacement of the three sets of simulation results; the right side is positive and the left is negative (Ball displacement_x). The black line segment above the prefabricated crack is the elements fracture produced during the loading process, which are the cracks generated during the fracture process.

3.2.2. The Destruction Process of Different Mesostructures. The conglomerate specimens with different mesostructures tend to exhibit different characteristics of failure responses produced by the varying external load. The curves on the number of the tensile cracks, shear cracks, and load value as a function of the crack tip opening displacement (CTOD) in the numerical simulation tests of three groups of conglomerates with different mesostructures are shown in Figure 12.

Through the observation of the test curves and the change rule of the mesostructure in the specimens, it can be established that the conglomerates can produce two kinds of cracks-tensile cracks and shear cracks, under the fracture toughness test. However, the main failure occurs when the tensile damage grows significantly. By observing the test curves of different groups, presence of three kinds of phenomena can be concluded:

(1) (In the Group A) There is only one load peak present when the crack propagates in the gravel, and the crack first produces tensile cracks, while a number of shear cracks are few. After the load reaches the peak value, the number of shear cracks increases gradually, but the number of tensile cracks tends to show a rapid surge

(2) (In the Group B) There is only one peak load present when the crack propagates in the matrix. Shear cracks and tensile cracks occur simultaneously at the initial stage of crack generation; but after reaching the peak load value, the tensile cracks continue to increase, while the appearance of shear cracks is halted

(3) (In the Group C) The crack penetrates through the gravel No. 1 and No. 2 and then propagates along gravel No. 3 (in the matrix), while the load exhibits multiple peaks. Noticeably, the shear cracks first appear before the load reaches the first peak value, and a number of new tensile cracks are few. At this point, the cracks pass through the gravel No. 1. The shear cracks continue to grow slowly during the subsequent load increase, but the tensile cracks increase rather sharply when the second load peak occurs, and the 


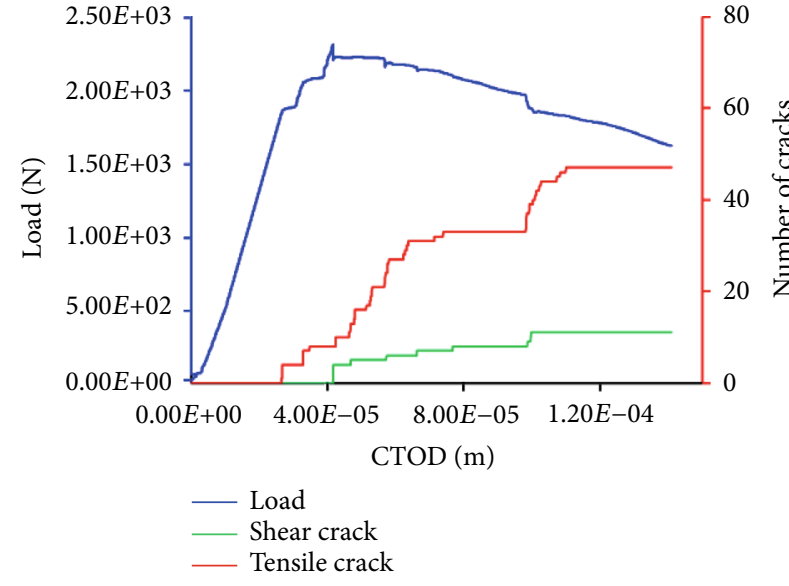

(a)

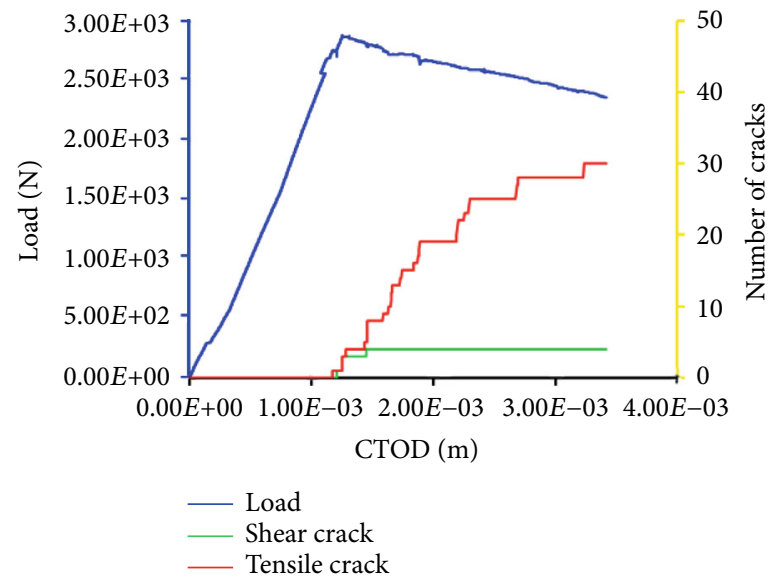

(b)

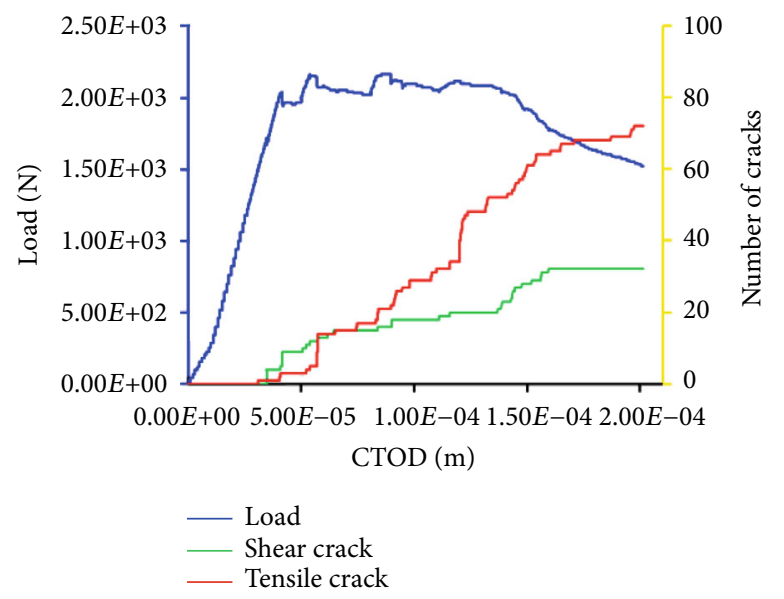

(c)

FIgURE 12: Curve of fracture toughness simulation test results. Shown in the figures are the curves of the variable (the load and the crack number) with the crack tip opening displacement (CTOD) of the three sets of experimental. The blue lines are the load. The green lines are the number of shear cracks. The red lines are the number of tensile cracks.

cracks propagate in the matrix as well. After that, the growth rate of tensile cracks gradually accelerates, gravel No. 2 gets eliminated gradually, and the cracks reenter the matrix. At this moment, the tensile cracks are still mainly generated in gravel No. 2 and the matrix above it. The newly added shear cracks are mainly concentrated near the boundary of gravel No. 3, and do not expand until the crack finally propagates along gravel No. 3 . Finally, the extension cracks appear at the boundary of gravel No. 3

Summarizing, when the cracks propagate in and out of the gravel, or from the matrix to the propagation along with the gravel, the load curves suffer multiple peaks. The cracks are mainly tensile, but shear cracks also transpire when crack propagation occurs around or through the gravel. The shear cracks do not increase after reaching a certain number, and the fracture mode returns to tensile failure.

3.3. Fracture Feature Unit. In the Groups A and B, the cracks only propagate in the gravel or in the matrix. However, the cracks in the Group C possess both the modes. Therefore, in this section, the Group C is selected as the research sub- ject to meticulously analyze the initiation and evolution of the mesostructure transpiring in it by recording the variations in the displacement field during the simulation. The concept of the research unit proposed by Yan et al. [35] is discussed as well.

It is assumed that near the crack tip, the area with stress greater than $30 \%$ of the crack tip stress is divided into a research unit, including the gravel particles and cement, and is named as the fracture feature unit. During the loading process, the mesoscopic damage of the conglomerate sample chiefly occurs within the fracture feature unit, and the damage form is only affected by the mesoscopic features of the fracture feature unit internally.

When the crack passes the gravel, the fine texture of the gravel particles inside the RU gradually gets damaged during the loading process and eventually breaks the gravel. When the crack bypasses gravel, the cementation between the gravel grain boundary inside the RU and the matrix (or other gravel boundary) gradually gets damaged during the loading process and eventually triggers the cementation failure. 


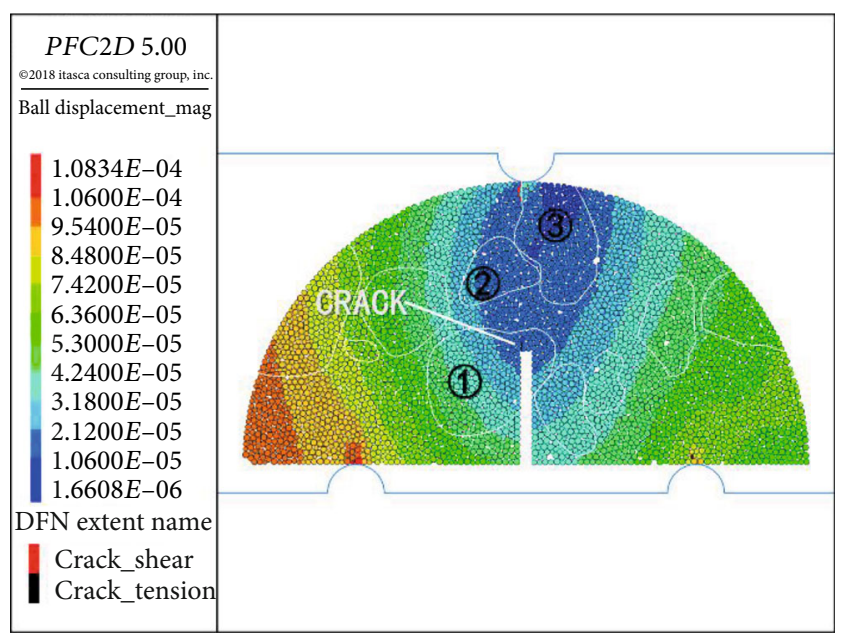

(a)

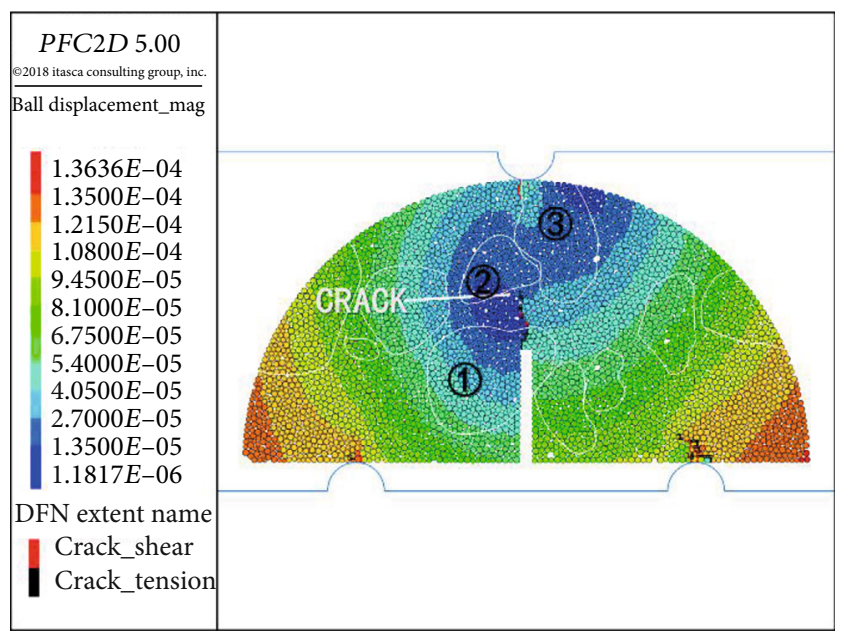

(c)

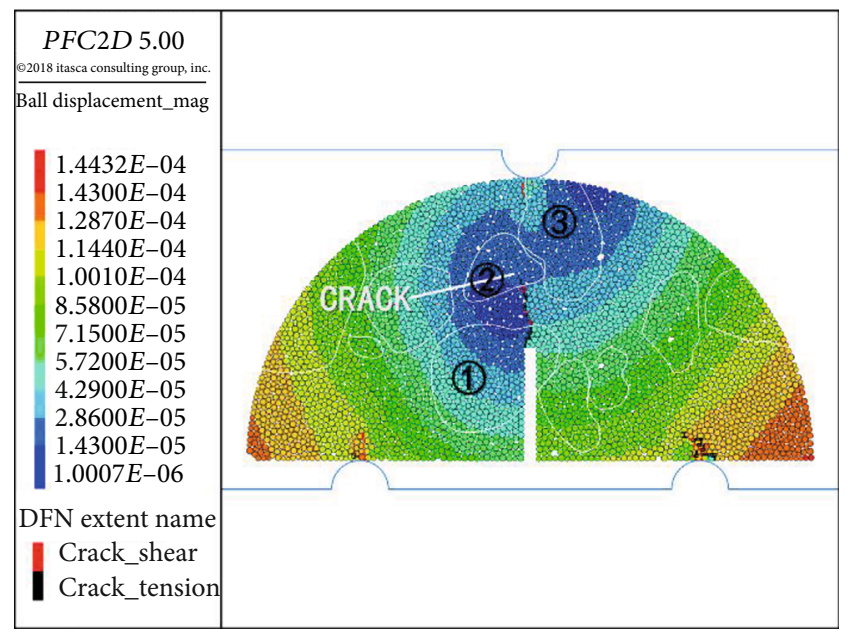

(e)

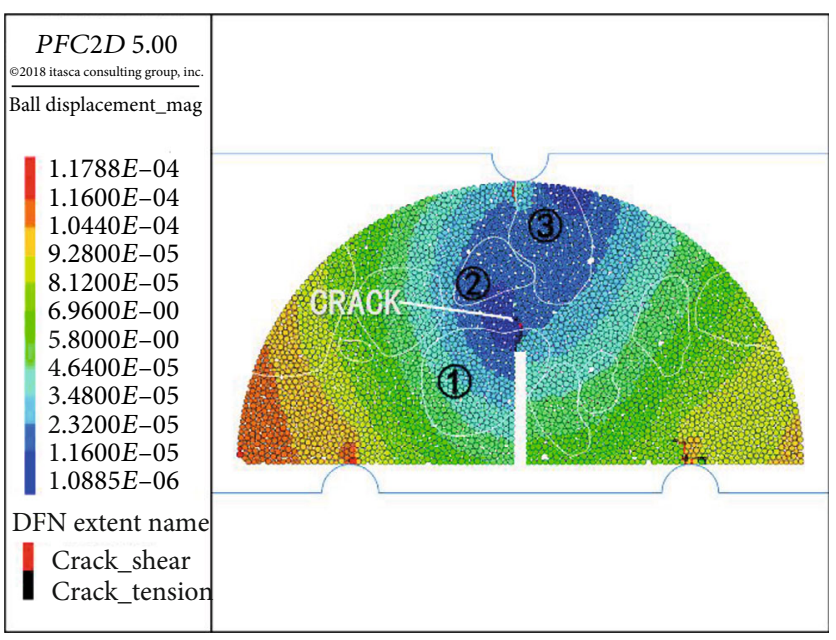

(b)

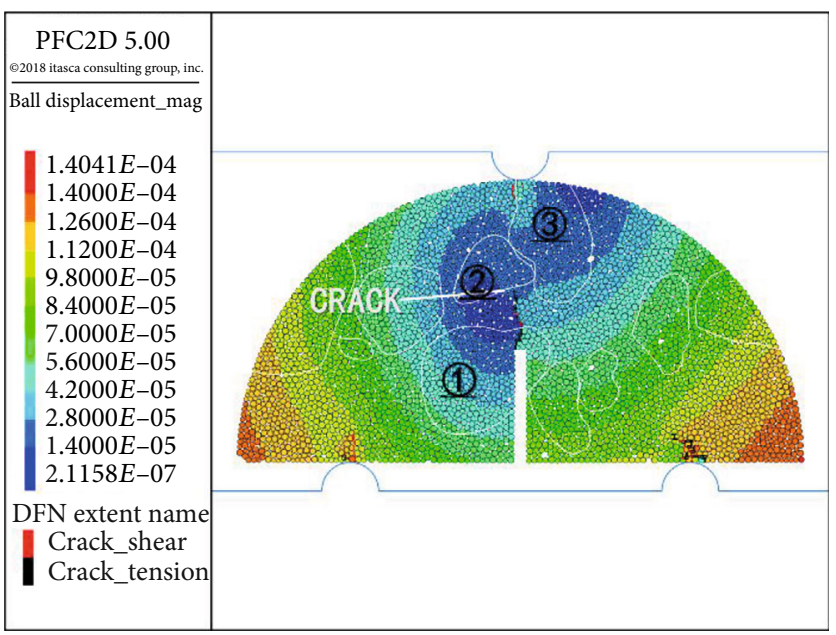

(d)

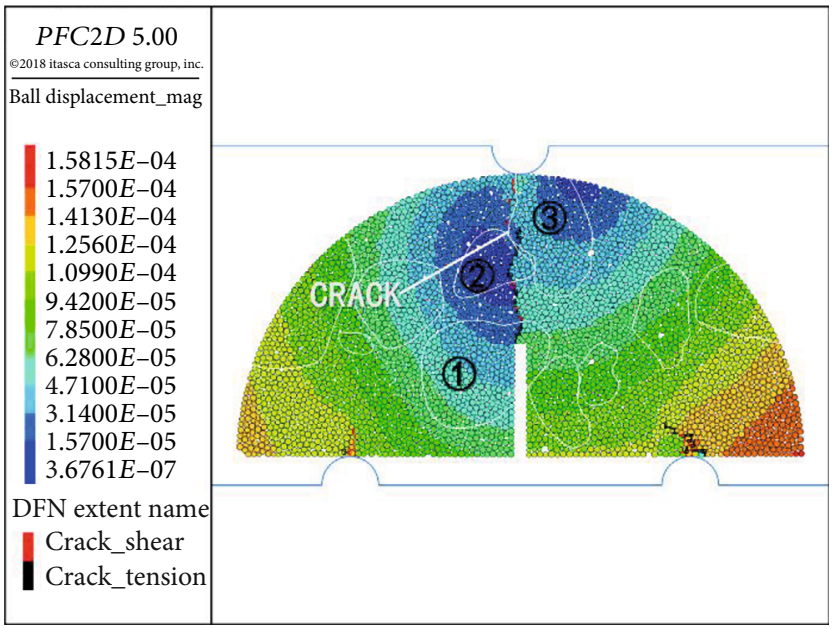

(f)

Figure 13: Continued. 


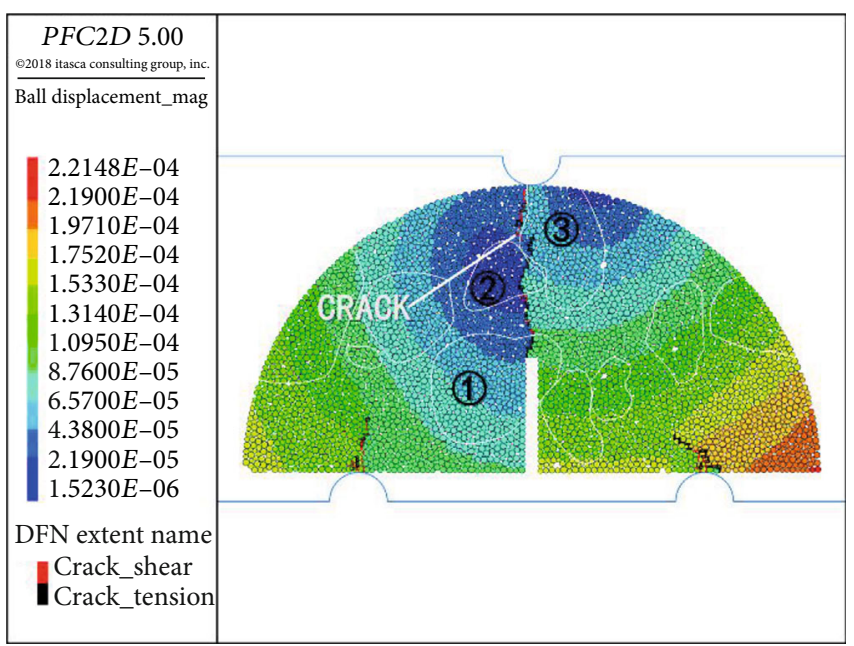

(g)

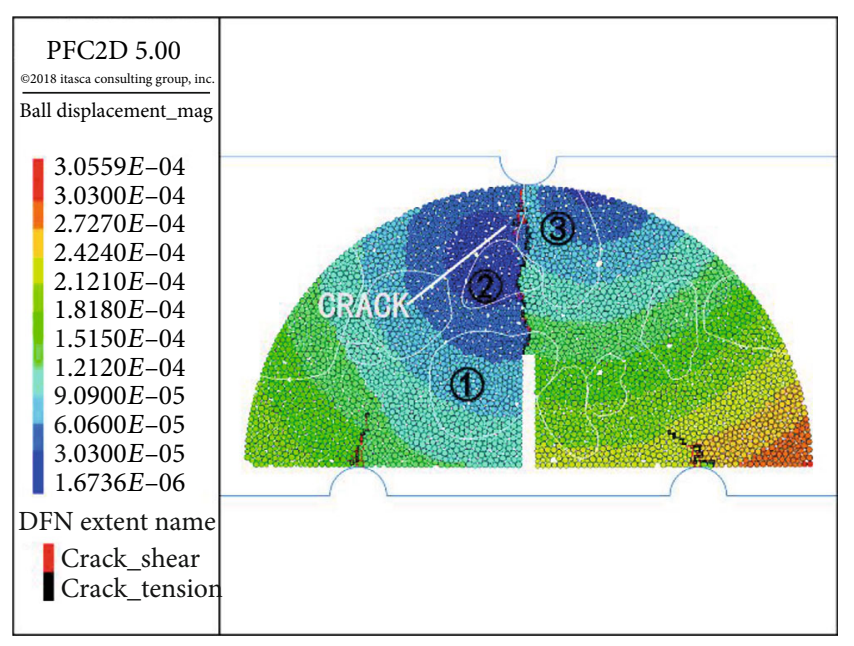

(h)

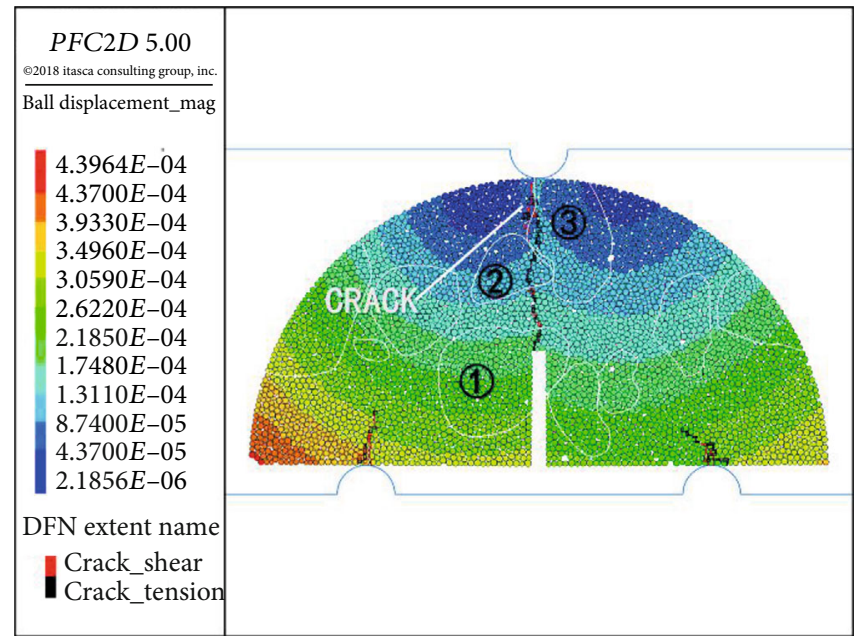

(i)

Figure 13: Test C crack growth process. The figures show the change trend of the displacement field (Ball displacement_mag) during the crack propagation process of the simulation of the Group C. The black and red lines above the prefabricated crack are the destruction of the bond chain of the bonding elements (balls), which represent the fracture crack.

Scrutinizing the sample after the test reveals that the propagation direction of the cracks in the conglomerate is quite ambiguous. This phenomenon induces variations in the hypothetical research unit. Unlike other rocks with sound homogeneity, such as sandstone, cracks in conglomerates tend to vary the direction of propagation on encountering gravel particles. This is due to the damage on the boundary surface of the gravel being uneven, and this uneven damage causes asymmetrical deformation of the specimen. Furthermore, the cumulative weakening effect of this uneven deformation alters the propagation path of the crack. When the crack propagation path changes, the old research unit undergoes changes as well, and the new research unit is formed. In this manner, the initiation and evolution process of the mesostructure take place within the conglomerate.

The Group C presents a rather uniform distribution of the displacement field due to the relative uniformity of the gravel distribution, which has been explained in the previous sections. Figures 13(a) and 13(b) represent the cracks propagated through the gravel No. 1. At this point, a continuous displacement field appears in the area above the crack tip and gradually gets divided into two connected fields. One of them has the gravel No. 1 and No. 2, as the center, while the center of the other one is gravel No. 3. Figures 13(c) and $13(\mathrm{~d})$ represent the cracks propagated in the matrix between gravel No. 1 and No. 2. At this point, the two displacement fields generated are slowly divided by the crack, but they remain connected at the tip of the crack. Figures 13(e) and 13(f) illustrate the cracks propagating via the gravel No. 2. At this moment, the center of the left displacement field gradually shifts upwards from the middle area of the gravel No. 1 and No. 2, and as the crack continues to grow, the displacement fields on both the sides get completely separated. At this point of time, the crack tip slowly approaches gravel No. 3. Subsequently, a large 
number of shear cracks are generated near the crack tip. Figures 13(g)-13(i) suggest that the cracks propagate from between gravel No. 2 and No. 3 to the left side of gravel No. 3 until the failure of the specimen occurs.

During this entire process, it was noticed that the displacement field near the gravel and the nearby matrix acted as a means for the destruction of the specimen. According to the basic principle of the PFC method, the interaction force between particles and the relative displacement between the particles exhibit a linear function. The displacement field in Figures 13(a)-13(i) is shown to be evenly segregated into 10 parts, from high to low. Theoretically, the variations in the displacement field can indicate the changes occurring in the stress field to a certain extent, with the generation of cracks in a specific area. With the increment of the load and the further extension of the crack, the shape of the key displacement field also tends to change simultaneously. This seems to be consistent with the research unit concept proposed by Yan et al. [35].

A further discussion about the fracture feature unit reveals that the mesostructure inside the specimen continues to vary as the crack expands. During the three-point bending fracture toughness test of the specimen, the crack propagation is seen to be closely associated with the bending deformation of the specimen and is ascertained to be affected by the bending stiffness. In a conglomerate, when the crack tip meets the gravel, the fracture extension direction is easy to deflect. This phenomenon induces a change in the morphology of the characteristic unit that influences the fracture behavior at the crack tip, and the local stiffness also suffers a change. At the onset of crack generation, the overall specimen stiffness does not undergo any drastic change, but the scale of the unit and the entire specimen appears different. The local stiffness of the unit changes on a substantial scale. This change in stiffness causes damage to the gravel boundary or within the gravel particles inside the unit, and the damage appears as shear failure between the particles. With the increment of the load, the deformation of the unit intensifies, and the local shear cracks finally fuse with the crack tip, giving rise to the tensile failure.

\section{Conclusions}

Employing the PFC numerical simulation of the three-point bending fracture toughness test for the semicircular specimens of the conglomerate, the following three aspects of understanding are deduced:

(1) The presence of gravel gives rise to the complexity exhibited by the mesostructure of the conglomerate. Conglomerate specimens with dissimilar mesostructures tend to diversify the destruction forms of the conglomerate

(2) In the fracture toughness test, the peak load tends to fluctuate a great deal. The numerical simulation of the fracture toughness obtained by the PFC method revealed the reason for the peak load fluctuation during the fracture propagation to be the constant penetration of the cracks in and out of the gravel. Due to the peculiarity of the conglomerate mesostructure, the fracture behavior usually does not befall instantly after the load value meets the peak. There- fore, when the mesostructure encountered by the tip changes during the crack propagation process, the load tends to change as well

(3) Fracture toughness simulation validated the rationality of the hypothetical research unit proposed by Yan et al. [35]. The evolution of the mesostructure inside the unit produces a significant impact on the macroscopic failure form of the conglomerate. The difference between the local stiffness and the overall stiffness of the conglomerate induces damage (i.e., shear cracks) at the boundary or between the gravel particles. As the damage accumulates, the final crack propagation path tends to change

\section{Data Availability}

The (simulation data) data used to support the findings of this study are available from the corresponding author upon request.

\section{Conflicts of Interest}

The authors wish to declare that there is no conflict of interest regarding the publication of this paper.

\section{Acknowledgments}

The authors wish to acknowledge Professor Zhang Guangqing of China University of Petroleum (Beijing). This work was financially supported by the National Natural Science Foundation of China (grant number 51704307, 51974338), the Major Science and Technology Projects for Strategic Cooperation between China National Petroleum Corporation (CNPC) and China University of Petroleum (Beijing) (ZLZX2020-01), and the China University of Petroleum (Beijing) (ZX20200119).

\section{References}

[1] Q. Meng, S. Zhang, X. Guo, X. Chen, and Y. Zhang, "A primary investigation on propagation mechanism for hydraulic fractures in glutenite formation," Journal of Oil and Gas Technology, vol. 32, no. 4, pp. 119-123, 2010.

[2] G. Li, L. Li, C. Tang, and Q. Meng, "Research on the mechanics of glutenite hydrofracturing crack propagation and gravel content influenced," in Paper presented at the: National Academic Conference on Rock Mechanics and Engineering Test and Testing Technology, Changchun, Jilin: China, 2012.

[3] P. Luo, Y. Li, Y. Jiang, and Y. Li, "Simulation study on extension path of hydraulic fracture of the sandy conglomerate," Petroleum Geology and Recovery Efficiency, vol. 107-110, pp. 114-122, 2013.

[4] Q. Meng, S. Zhang, P. Chen, L. Wang, and J. Zhang, "Practice of fracturing and reforming of gravel reservoir in Shengli oilfield," in Paper presented at the: The Fifth National Conference on Deep Rock Mechanics and National Petroleum Engineering Theory and Technology Progress Forum, 2007Beijing: China.

[5] L. Li, G. Li, Q. Meng, H. Wang, and Z. Wang, "Numerical simulation of propagation of hydraulic fractures in glutenite formation," Rock and Soil Mechanics, vol. 5, pp. 1501-1507, 2013. 
[6] D. Li and L. N. Y. Wong, "The Brazilian disc test for rock mechanics applications: review and new insights," Rock Mechanics Rock Engineering, vol. 46, no. 2, pp. 269-287, 2013.

[7] N. Li, S. Zhang, X. Ma et al., "Experimental study on the propagation mechanism of hydraulic fracture in glutenite formations," Chinese Journal of Rock Mechanics and Engineering, vol. 36, pp. 2383-2392, 2017.

[8] W. Yang and H. Tan, "Micromechanics and nanomechanics for a fracture process," China Science Foundation, vol. 7, pp. 249-254, 1993.

[9] Z. Bazant and E. P. Chen, "Scaling of structural failure," Advances in Mechanics, vol. 50, pp. 593-627, 1999.

[10] Y. Bai, H. Wang, M. Xia, and F. Ke, "Statistical mesomechanics of solid," Advances in Mechanics, vol. 36, pp. 286-305, 2006.

[11] J. Zhou, Z. Wang, J. Zhang, and Y. Deng, "Macro-meso research on mechanical behavior of gravelly soil under various stress paths," Chinese Journal of Rock Mechanics and Engineering, vol. 32, pp. 1721-1728, 2013.

[12] X. Duan and L. Liu, "Discrete element simulation of expansibility of gravel-modified expansive soil," Sichuan Building Materials, vol. 43, pp. 20-22, 2017.

[13] S. Zhan, Z. Chen, T. Wang, Z. Weng, and S. Zheng, "Discuss on granule mechanics numerical simulation of shield tunneling in gravel strata," Paper presented at the 10th academic and technical symposium on Cross-Strait tunnel and underground engineering, 2011, Ürümqi, 2011, 2011.

[14] H. Fan, Test Research on Structure Characteristics and Mechanical Characteristics of Xiyu Conglomerate, Beijing Jiaotong University, 2016.

[15] M. Jiang, Z. Shen, and J. Wang, "A novel three-dimensional contact model for granulates incorporating rolling and twisting resistances," Computers and Geotechnics, vol. 65, pp. 147-163, 2015.

[16] N. Belheine, J. P. Plassiard, F. V. Donze, F. Darve, and A. Seridi, "Numerical simulation of drained triaxial test using 3D discrete element modeling," Computers Geotechnics, vol. 36, no. 1-2, pp. 320-331, 2009.

[17] L. Rothenburg and R. J. Bathurst, "Numerical simulation of idealized granular assemblies with plane elliptical particles," Computers Geotechnics, vol. 11, no. 4, pp. 315-329, 1991.

[18] T. T. Ng, "Numerical simulations of granular soil using elliptical particles," Computers Geotechnics, vol. 16, no. 2, pp. 153169, 1994.

[19] C. F. Wang and C. Y. Wang, "A packing generation scheme for the granular assemblies with 3D ellipsoidal particles," International Journal for Numerical and Analytical Methods in Geomechanics, vol. 23, no. 8, pp. 815-828, 1999.

[20] M. R. Kuhn, "Smooth convex three-dimensional particle for the discrete-element method," Journal of Engineering Mechanics, vol. 129, no. 5, pp. 539-547, 2003.

[21] B. Yan, "Three-dimensional ellipsoidal discrete element modeling of granular materials and its coupling with finite element facets," Engineering Computations, vol. 27, p. 519, 2010.

[22] A. A. Peña, A. Lizcano, F. Alonso-Marroquin, and H. J. Herrmann, "Biaxial test simulations using a packing of polygonal particles," International Journal for Numerical and Analytical Methods in Geomechanics, vol. 32, no. 2, pp. 143-160, 2008.

[23] G. Mollon and J. Zhao, "Fourier-Voronoi-based generation of realistic samples for discrete modelling of granular materials," Granular Matter, vol. 14, no. 5, pp. 621-638, 2012.
[24] Y. Liu, X. Li, and S. Wu, "Numerical simulation of particle crushing for rockfill of different particles shape under rolling compaction," Rock and Soil Mechanics, vol. 35, pp. 32693280, 2014.

[25] E. Azema, F. Radjai, and G. Saussine, "Quasistatic rheology, force transmission and fabric properties of a packing of irregular polyhedral particles," Mechanics of Materials, vol. 41, pp. 729-741, 2009.

[26] S. J. Lee, E. G. Nezami, and Y. M. A. Hashash, "Simulation of triaxial compression tests with polyhedral discrete elements," Computers and Geotechnics, vol. 43, pp. 92-100, 2012.

[27] G. Liu, G. Rong, J. Peng, D. Hou, and C. Zhou, "Mechanical behaviors of rock affected by mineral particle shapes," Chinese Journal of Geotechnical Engineering, vol. 35, pp. 540-550, 2013.

[28] L. Kong and R. Peng, "Particle flow code simulation of the influence of particle shape on mechanical properties of quasi-sands," Chinese Journal of Rock Mechanics and Engineering, vol. 30, pp. 2112-2119, 2011.

[29] P. Wang and J. Liu, "Effect of particle shape on the shear behavior of open-graded crushed aggregate," Rock and Soil Mechanics, vol. 38, pp. 2198-2202, 2017.

[30] C. Lin and D. Ling, "Simulation of real particle shape in PFC numerical analysis," Journal of Central South University(Science and Technology), vol. 48, pp. 2425-2431, 2017.

[31] P. A. Cundall, "A computer model for simulating progressive, large-scale movements in block rock systems," Proceedings of Symposium of International Society of Rock Mechanics, 1971, Nancy: France, 1971, 1971.

[32] P. A. Cundall and O. D. L. Strack, "A discrete numerical model for granular assemblies,” Geotechnique, vol. 29, no. 1, pp. 4765, 1979.

[33] P. A. Cundall, "Computer simulations of dense sphere assemblies," Studies in Applied Mechanics, vol. 20, pp. 113-123, 1988.

[34] P. A. Cundall and D. O. Potyondy, "A bonded-particle model for rock," International Journal of Rock Mechanics Mining Sciences, vol. 41, pp. 1329-1364, 2004.

[35] Y. Yan, G. Zhang, S. Li, and Y. Nie, "Study on the influence of conglomerate meso-structures characteristics on crack propagation," Proceedings of the 53rd U.S. Rock Mechanics/geomechanics Symposium. American Rock Mechanics Association, 2019, New York City, New York: U.S., June 2019, 2019.

[36] X. Liu, J. Xiong, L. Liang, and X. You, "Rock mechanical characteristics and fracture propagation mechanism of sandy conglomerate reservoirs in Baikouquan formation of Mahu sag," Xinjiang Petroleum Geology, vol. 39, pp. 83-91, 2018.

[37] W. Hu, Research on Mechnical Behavior of Jointed Rock Mass Based on Smooth-Joint Contact Model, Wuhan University, 2017. 